\title{
GROUND SUBSIDENCE MONITORING WITH MT-InSAR AND MECHANISM INVERSION OVER XI'AN, CHINA
}

\author{
M. M. Peng ${ }^{1}$, C. Y. Zhao ${ }^{1,2 *}$, Q. Zhang ${ }^{1,3}$, J. Zhang ${ }^{1,2}$, Y. Y. Liu ${ }^{1}$ \\ ${ }^{1}$ School of Geology Engineering and Geomatics, Chang'an University, Xi'an 710054, China; mmpeng_insar@163.com (M. \\ P); zhaochaoying@163.com (C. Z); zhangqinle@263.net.cn (Q. Z); 305628489@qq.com (J. Z); yuanyuanolay@163.com (Y. L) \\ ${ }^{2}$ State Key Laboratory of Geo-Information Engineering, Xi’an, 710054, China \\ ${ }^{3}$ National administration of surveying, mapping and geo-information, Engineering research center of national geographic \\ conditions monitoring, Xi'an, 710054, China
}

Commission III, WG III/3

KEY WORDS: Xi'an, MT-InSAR, Land subsidence, Subway line No.3, Inversion

\begin{abstract}
:
The ancient Xi'an, China, has been suffering severe land subsidence and ground fissure hazards since the 1960s, which has affected the safety of Subways. Multi-sensor SAR data are conducted to monitor the latest complex ground deformation and its influence on subway line No.3 over Xi'an. Annual deformation rates have been retrieved to reveal the spatiotemporal evolution of ground subsidence in Xi'an city from 2013 to 2017 . Meanwhile, the correlation between land subsidence and ground fissures are analyzed by retrieving the deformation differences in both sides of the fissures. Besides, the deformation along subway line No. 3 is analyzed, and the fast deformation section is quantitatively studied. Finally, a flat lying sill model with distributed contractions is implemented to model the InSAR deformation over YHZ subsidence center, which manifests that the ground deformation is mainly caused by groundwater withdrawal.
\end{abstract}

\section{INTRODUCTION}

The ancient Xi'an, located in the middle of Wei River Basin (Figure 1), is the capital of Shaanxi Province China. The urban Xi' an is bounded by the Chan River and Ba River to the east, the Jv River to the west, Wei River to the north and the Qinling Mountains to the south. The overall terrain of Xi'an gradually inclines from the southeast to the northwest, and the landform gradually transforms from loess tableland terraces to the flood plain. A series of normal faults have been developed around this city, among which the Lintong-Chang'an fault is the most active one (Peng et al., 2016). Along with the economic development and urban extension, severe land subsidence and ground fissures have occurred in Xi' an since 1960s (Zhang et al., 2009; Zhao et al., 2008; Qu et al., 2014). The maximum cumulative land subsidence has reached approximately $3 \mathrm{~m}$, and 14 ground fissures have emerged throughout the city in an east-north-east (ENE) direction, which have caused severe damages to the infrastructures, such as buildings, municipal pipelines, roads, bridges and metro railway.

Many researchers have conducted ground subsidence and fissures monitoring, and obtained valuable data using conventional ground-based techniques since 1959 including leveling and GPS (Zhu et al.,2005; Zhang et al., 2009). Since the beginning of 1990s, Interferometric SAR (InSAR) has become a powerful tool for measuring surface deformation induced by various hazards (Massonnet et al., 1993; Lu \&
Dzurisin, 2014; Qu et al., 2014; Kang et al., 2017). To overcome the limitations of conventional InSAR including decorrelation and atmospheric artifacts, advanced multiinterferogram InSAR (MT-InSAR) techniques such as Persistent Scatterers InSAR (PSInSAR) and Small Baseline Subset (SBAS) InSAR have been developed to map timeseries land surface displacements (Ferretti et al., 2001; Berardino et al., 2002).

Xi'an has been studied by several researchers with InSAR and/or ground-based geodetic techniques. Zhang et al. (2009) studied the spatiotemporal evolution and mechanism of land subsidence and ground fissure activities during 1992-2006 by using both GPS and InSAR observations. Zhao et al. (2008, 2009) studied the evolution of land subsidence during 19922007 by using 15 ERS-1/2 and Envisat data, and analyzed the land subsidence during 2005-2006 by using 7 Envisat images. $\mathrm{Qu}$ et al. (2014) studied the spatiotemporal evolution of land subsidence and ground fissures during 2005-2012 with multiple SAR datasets as well as leveling, GPS and groundwater data. With the urban extension, land subsidence and ground fissure develop continuously over Xi' an. However, few researches on ground subsidence and fissure activity can be found in Xi'an after 2012. Furthermore, no specific researches on the deformation of Xi'an metro lines, though it has been successfully reported in Beijing (Chen et al., 2017; $\mathrm{Ge}$ et al.,2016), Shenzhen (Xu et al., 2016), Shanghai (Perissin et al., 2012) with advanced InSAR techniques.

\footnotetext{
* Corresponding author
} 


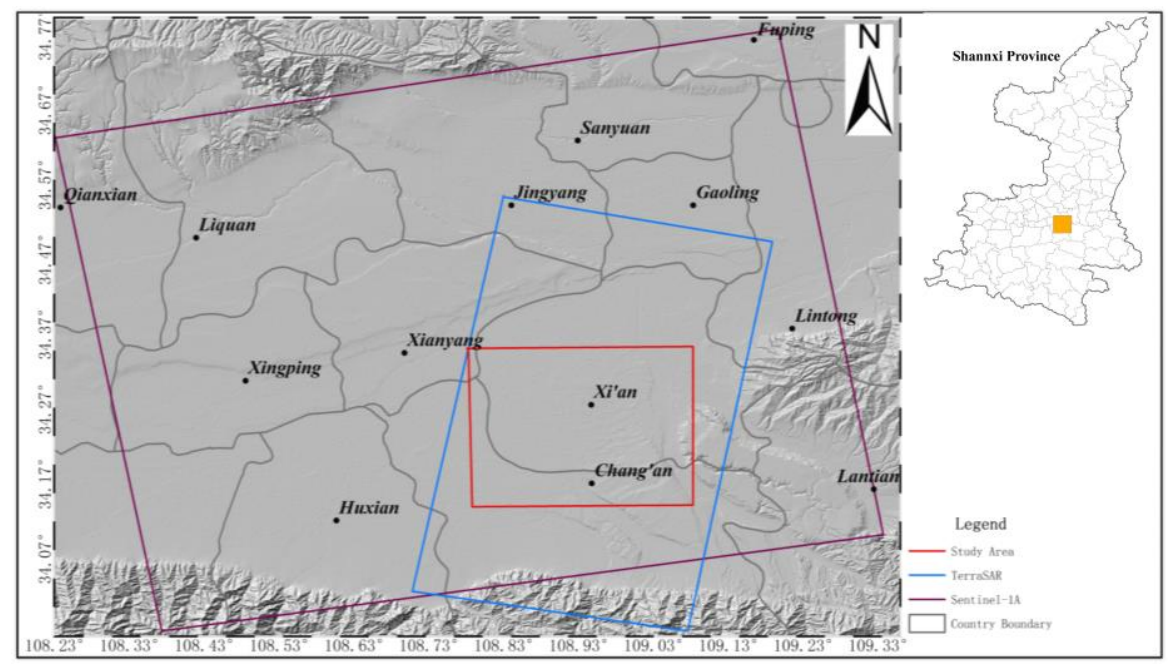

Figure 1. Location of the Xi' an city, where study area is shown in red rectangle, other two polygons show the SAR data coverage. The map of Shaanxi Province is an inset on the top-right corner.

\section{DATASETS}

In order to reveal the land subsidence over Xi'an from 2014 to 2017, seventy SAR images in two stacks are involved, including 25 descending-track TerraSAR-X data acquired from December 2012 to May 2015 and 45 ascending-track Sentinel-1A data acquired from June 2015 to October 2017. The coverages of the two data are shown in Figure 1 and the detailed parameters are summarized in Table 1. External DEM data from Shuttle Radar Topography Mission-1 (SRTM) with a spatial resolution of $30 \mathrm{~m}$ provided by NASA is used to simulate and remove the topographic phases.

Sentinel-1A Interferometric Wide swath (IW) Single Look Complex (SLC) products are used in this study. The IW mode is gathered using the novel Terrain Observation with Progression Scans (TOPS) in azimuth SAR imaging technique (Holzner and Bamler, 2002; Torres et al., 2012). The level-1 IW image is provided as three separate sub-swaths (IW1, IW2, IW3), and each of them consists of a series of bursts. The accuracy of the coregistration for Sentinel-1 TOPS InSAR processing in azimuth direction must reach one thousandth of one pixel, which is much more stringent than that for the stripmap products (De Zan et al., 2014). A wide-area IW product should be created with two steps, that is debursting and merging (Sowter et al, 2016). The former processing concatenates the individual bursts from one sub-swath into a single debursting sub-swath, and then several sub-swaths will be merged into one single wide-swath product.

\begin{tabular}{lll}
\hline Sensor & TerraSAR-X & Sentinel-1A \\
\hline Band & $\mathrm{X}$ & $\mathrm{C}$ \\
Wavelength $(\mathrm{cm})$ & 3.1 & 5.6 \\
Incident angle $\left(^{\circ}\right)$ & 26.5 & $29-46$ \\
Slant range spacing $(\mathrm{m})$ & 0.9 & 2.3 \\
Azimuth spacing $(\mathrm{m})$ & 2 & 14.1 \\
Pass direction & descending & ascending \\
$\begin{array}{l}\text { Spatial coverage of full } \\
\text { scene }\end{array}$ & $30 \times 50$ & $250 \times 250$ \\
(range $\times$ azimuth in & & \\
km) & & \\
Number of images & 25 & 45 \\
Date period & $20121207-$ & $20150620-$ \\
\hline
\end{tabular}

20150528 20171031

Table 1. Basic parameters of the two SAR data stacks

\section{METHODOLOGY}

In this study, Small baseline subsets (SBAS) methods is used to map the surface deformation rate from 2013 to 2017 over Xi'an. StaMPS and GAMMA softwares are applied to TerraSAR-X data and Sentinel-1A data, respectively.

SBAS-InSAR relies on adequate combinations of multiple small baseline interferograms to increase the temporal sampling and deformation monitoring accuracy (Berardino et al., 2002; Lanari et al., 2004). The unwrapped phase at pixel $(\mathrm{x}, \mathrm{r})$ in the $k$ th differential interferogram can be written in the following form.

$$
\begin{aligned}
& \delta \varphi_{(x, r)}=\varphi_{(x, r)}\left(t_{B}\right)-\varphi_{(x, r)}\left(t_{A}\right) \\
& \quad \approx \delta \varphi_{(d e f, x, r)}+\delta \varphi_{(\epsilon, x, r)}+\delta \varphi_{(\alpha, x, r)}+\delta \varphi_{(n, x, r)}
\end{aligned}
$$

where, $\varphi_{(x, r)}\left(t_{B}\right)$ and $\varphi_{(x, r)}\left(t_{A}\right)$ present the phases at SAR acquisition dates $t_{B}$ and $t_{A}\left(t_{A}<t_{B}\right) ; \delta \varphi_{(\text {def }, x, r)}$ is the deformation phase component corresponding to the target movement along the satellite line-of-sight (LOS) direction; $\delta \varphi_{(\epsilon, x, r)}$ is the topographic error; $\delta \varphi_{(a, x, r)}$ is the phase signal induced by the difference in atmospheric path delay between two observations and $\delta \varphi_{(n, x, r)}$ is the noise phase. Differential interferograms generation, coherent point selection, network formation, phase unwrapping, and temporal-spatial filtering are included to obtain the time series deformation.

StaMPS SBAS can work on single-look images to identify single-look slow-varying filtered phase (SFP) pixels, whose phases decorrelate little over short time intervals (Hooper, 2008; Qu et al., 2014). $\gamma_{x}$, the representation of variations in the residual phase at the SFP candidate pixel, is defined as StaMPS.

$$
\gamma_{x}=\frac{1}{N}\left|\sum_{i=1}^{N} \exp \left\{\sqrt{-1}\left(\psi_{x, i}-\Delta \hat{\psi}_{\theta, x, i}^{u}-\hat{\psi}_{x, i}\right)\right\}\right|
$$

where $\mathrm{N}$ is the number of interferograms, $\psi_{x, i}$ is the wrapped phase of pixel $\mathrm{x}$ in the $i$-th interferogram, $\hat{\psi}_{\theta, x, i}^{u}$ is the 
estimated spatially uncorrelated look angle error term and $\hat{\psi}_{x, i}$ is the estimate of the spatially-correlated term. After each iteration, the root-mean-square change in $\gamma_{x}$ is calculated by Equation (2). When the change is less than a given threshold, the iteration will be stopped.

Once the SFPs have been selected, their phases are corrected for spatially uncorrelated look angle (SULA) error by subtracting the estimated values, that is the DEM error. Then a three-dimensional phase unwrapping is used on the corrected phase. Optionally, a low-pass filtering in space and follow a high-pass filter in time can be applied to the unwrapped interferometric phases in order to remove the remaining errors (orbit and atmosphere artifacts errors). Finally, time-series deformation measurements at each SFP pixel are produced.

The SAR data are paired to form interferograms with high coherence following small baseline rules. We construct a total of 160 interferograms including 29 from TerraSAR-X and 131 to study the deformation in Xi'an from 2013 to 2017.

\section{RESULTS AND ANALYSIS}

\subsection{Land Subsidence rate map}

Annual vertical deformation maps from 2013 to 2017 over Xi'an are obtained with TerraSAR-X data and Sentinel-1A data. Fig.2 (a, b) shows the deformation maps in 2013 and 2015, produced by TerraSAR-X data, and Fig.2 (c, d) shows the results in 2015 and 2017, produced by Sentinel-1A data.

It can be seen in Figure 2 that the subsidence funnels were mainly located in the southwest and southeast of Xi' an from 2013 to 2017, including Yuhuazhai (YHZ hereinafter), Qujiang (QJ hereinafter), Sanyaocun (SYC hereinafter) and Electronic Mall (EM hereinafter). Quantitatively, the spatial distribution of the four subsidence centers has no significant

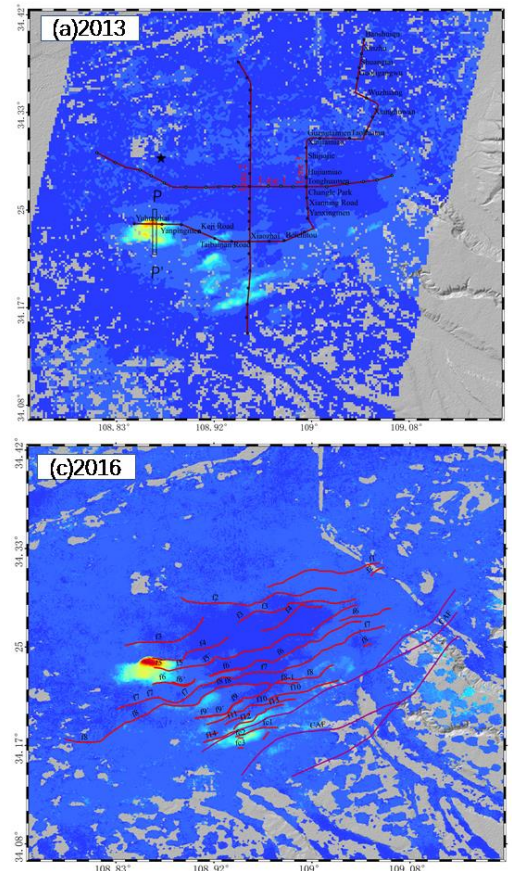

changes except YHZ from 2013 to 2017, and the whole subsidence in the magnitude shows an increase and decrease subsequent trend. The subsidence rate in the four subsidence centers all increase from 2013 to 2015, then keep stable from 2015 to 2016, and began to decrease from 2016 to 2017. With the development of urban construction, the largest land subsidence occurs at YHZ, with the subsidence rate increasing from $135 \mathrm{~mm} / \mathrm{a}$ in 2013 to $177 \mathrm{~mm} / \mathrm{a}$ in 2016, and decreases to $114 \mathrm{~mm} / \mathrm{a}$ in 2017 . It still is the biggest subsidence center in Xi'an city, which has caused serious impacts on the operation of subway line No.3.

Many previous studies suggested that land subsidence over $\mathrm{Xi}$ 'an was mainly due to underground water pumping (Peng et al., 2012, 2016; Qu et al., 2014). And ground fissures in Xi'an were activated as a result of soil surface tension due to land subsidence caused by ground water withdrawal (Qu et al., 2014). In order to analyze the relationship between the ground fissures and the regional deformation over the YHZ subsidence center, the annual deformations rate along the profile PP' (Fig.2 (a)) are extracted and shown in Fig. 3. There are obvious different surface displacements crossing two sides of the fissures, which demonstrates a strong correlation between ground fissures and observed subsidence in YHZ. Comparing to the deformation rate differences between the two sides of the ground fissures, the fissure $\mathrm{f} 4$ is the most active one. The western sections of $\mathrm{f} 4, \mathrm{f5}$ and $\mathrm{f} 6$ are parallel to the Chang'an-Lintong fault, one of the main active faults in the region. Moreover, significant amount of land subsidence over YHZ during 2013-2017 accelerated the development of ground fissures, making fissures $\mathrm{f} 4$ and $\mathrm{f5}$ extend further westward and present horizontal direction. Subsidence-triggered fissures can cause localized surface displacements and aggravate localized subsidence, indicating that land subsidence and ground fissures mutually promote each other in Xi'an.

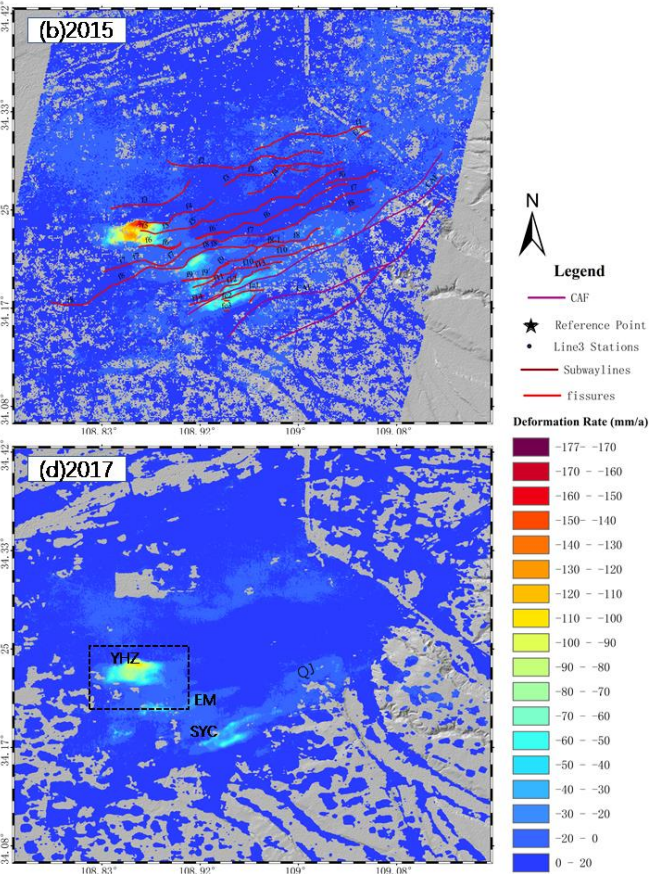

Figure 2. Average vertical deformation rate maps of Xi'an from 2013 to 2017, derived from TerraSAR-X (a-b) and Sentinel-1A (c-d). Black Star indicates the reference point. 


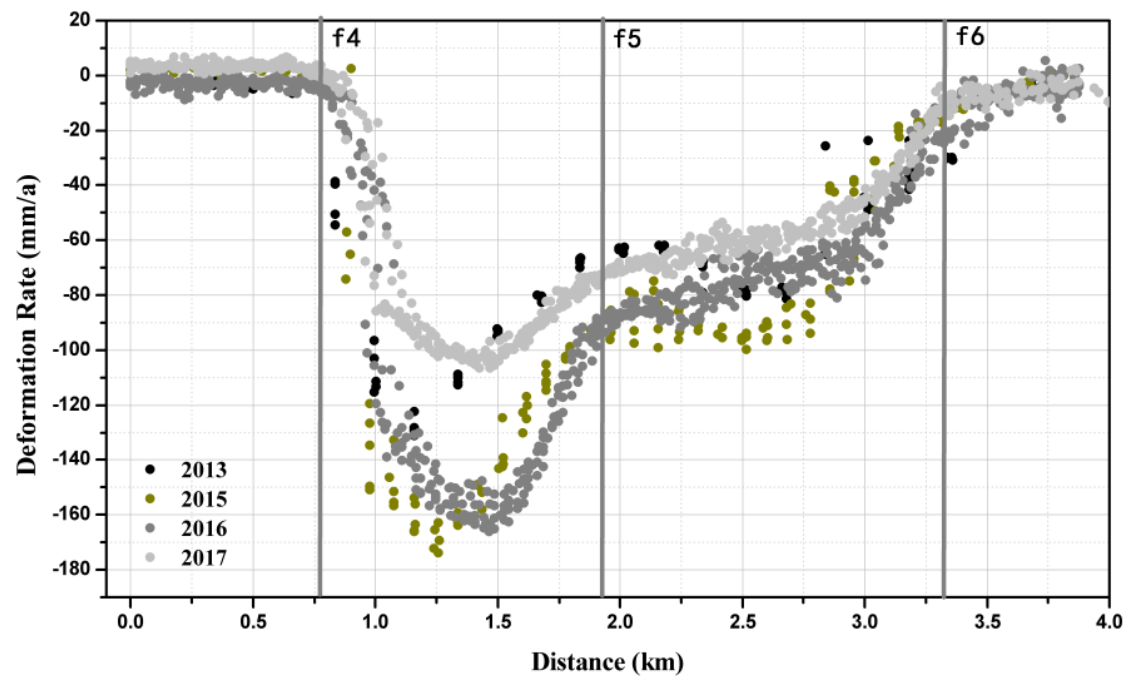

Figure 3. Annual deformation rate along the profile PP' from 2013 to 2017, whose position is marked with black solid box in Fig.2 (a). The gray lines represent the location of fissures.

\subsection{Deformation analysis along subway line No. 3}

At the end of 2017, a total of three subway lines (lines No. 1, 2 and 3) are operational and five subway lines are under construction in Xi'an. As subway line No. 3 excavated fully in 2012 and operated in November 2016, the deformation of it is analyzed from 2013 to 2017 . The maximum subsidence along line No. 3 occurred between Yanpingmen and YHZ stations.

Fig 4 shown the subsidence along Xi'an subway line No.3 from Taohuatan to YHZ station, and the time series results of which demonstrate a distinct temporal change of subsidence during the construction and operation periods. The fast subsidence occurred during the construction period, i.e. from $135 \mathrm{~m} / \mathrm{a}$ in 2013 to $177 \mathrm{~mm} / \mathrm{a}$ in 2016 , and rebounded to $114 \mathrm{~mm} / \mathrm{a}$ in 2017 , which indicates that the land subsidence rate has certain correlation with subway construction.

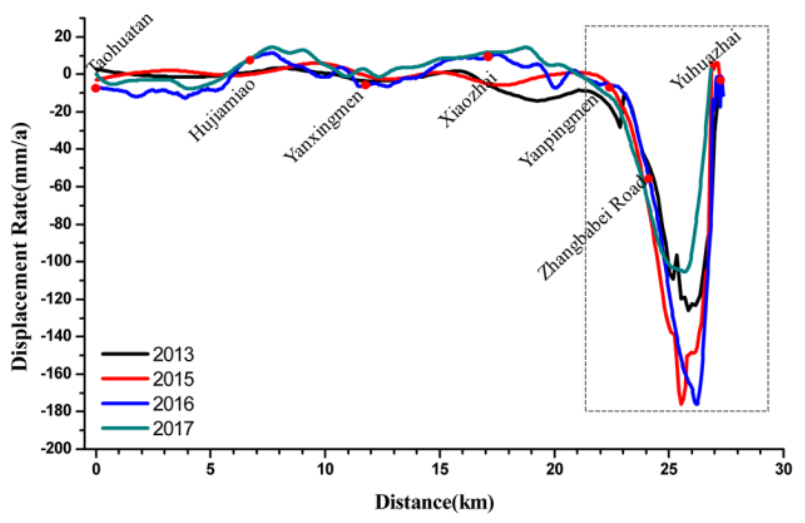

Figure 4. Deformation profile along subway line No. 3. The gray dash box represents the maximum subsidence change.

\subsection{Subsidence mechanism Inversion}

To better reveal the mechanism of the complex deformation in YHZ subsidence center, a flat lying sill with distributed contractions embedded in a homogenous elastic half space is employed to model it (Okada, 1985). To this end, we focus on a relative small region shown as the dashed black rectangle in Fig. 2 (d) as the inversion study area.

First, the quad-tree algorithm is used to down-sample the InSAR-derived deformation results to accelerate modeling processing. Six parameters, that is center coordinate $\mathrm{x}, \mathrm{y}$, length, width, depth, and dip angle are set to define the model (see table 1), which is defined by the root mean square misfit from the residuals between the observed and modeled data ( $\mathrm{Lu}, 2010)$. The patches of the distributed contraction sources are set as $0.15 \mathrm{~km} \times 0.15 \mathrm{~km}$. The depth of the model is fixed at $200 \mathrm{~m}$ based on the average depth of pumping wells (Peng, 2012). Fig. 5(b) shows that the magnitude and shape of the modeled deformation matches well the observed measurements. The root-mean-square error (RMSE) between the observed and modeled interferograms is chosen as the prediction-fit criterion. Fig.5 (c) shows the residuals between the observed and modeled interferograms, and the RMSE of which is $1.98 \mathrm{~mm}$. The correlation coefficient between the observed and modeled interferograms reaches up to $99 \%$. Therefore, YHZ subsidence center in 2017 can be explained as the excessive groundwater exploitation at the depth around 200 meters from the above-mentioned analysis.

\begin{tabular}{llllll}
\hline $\begin{array}{l}\mathrm{X} \\
(\mathrm{km})\end{array}$ & $\begin{array}{l}\mathrm{Y} \\
(\mathrm{km})\end{array}$ & $\begin{array}{l}\text { Depth } \\
(\mathrm{km})\end{array}$ & $\begin{array}{l}\text { Length } \\
(\mathrm{km})\end{array}$ & $\begin{array}{l}\text { Width } \\
(\mathrm{km})\end{array}$ & $\begin{array}{l}\text { Dip angle } \\
\left({ }^{\circ}\right)\end{array}$ \\
\hline 4 & 2.2 & 0.2 & 9 & 7 & 0 \\
\hline \multicolumn{7}{c}{ Table 2. Geometric parameters used in the sill inversion }
\end{tabular}
model

This model has been used successfully in Qingxu, China (Liu et al., 2018). Thus, the study will enrich the land subsidence research in $\mathrm{Xi}$ 'an. 


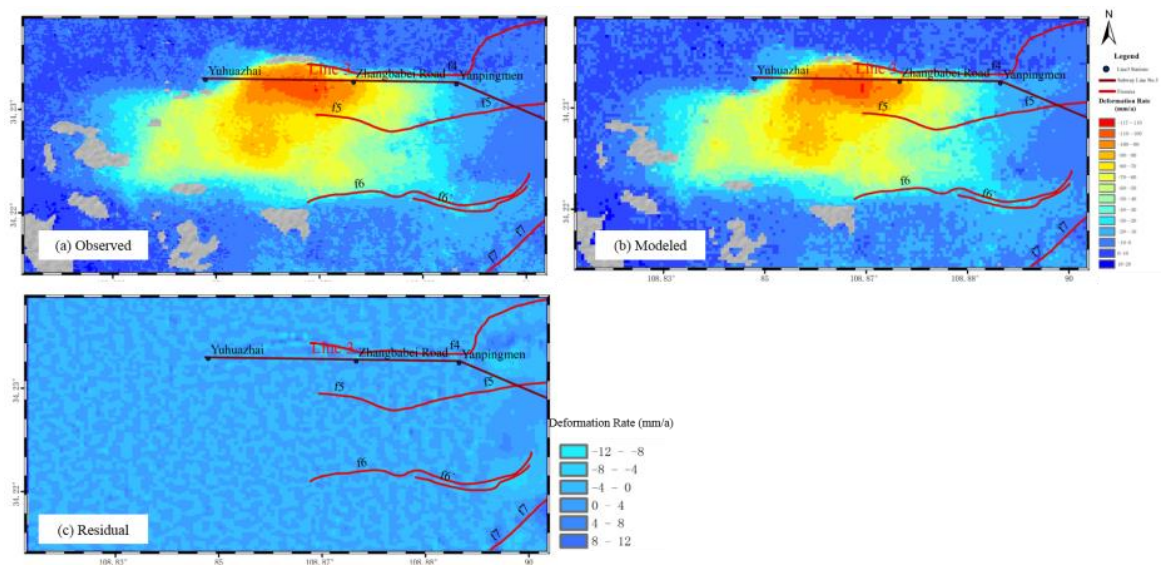

Figure 5. (a) The vertical deformation rate in 2017 over YHZ subsidence zone; (b) best-fitting model from a flat-lying distributed rectangle source in an elastic half-space; (c) residuals between the observed and modeled deformation. The red lines represent the ground fissures in the study area.

\section{CONCLUSIONS}

Multisensor SAR datasets have been successfully applied to map the land subsidence in Xi'an from 2013 to 2017. Four main subsidence centers are detected, and the land subsidence spatiotemporal characteristics are also revealed. The correlation between land subsidence and fissures is explained by analyzing the deformation along the profile. The time series deformation along the subway line No.3 is obtained, which shows us that the fast subsidence occurred during the excavation periods and remained stable in operation stage. Finally, a flat lying sill model is used to land subsidence mechanism inversion in YHZ, which manifests the ground deformation is mainly caused by groundwater withdrawal.

\section{ACKNOWLEDGEMENTS}

The authors would like to thank the European Space Agency for providing the Sentinel-1A SAR data freely. This work is jointly supported by the National Natural Science Foundation of China NSFC (Grant No. 41731066, 41628401 and 41772365 ) and the Ministry of Land \& Resources (China) projects (DD20160264).

\section{RERERENCES}

Berardino, P., Fornaro, G., Lanari, R., Sansosti, E. 2002. A new algorithm for surface deformation monitoring based on small baseline differential SAR interferograms. IEEE Trans. Geosci. Remote Sensing. 40(11), pp. 2375-2383.

Chen, W.F., Gong, h.l., Chen, B. B., Liu, K.S., Gao, M., Zhou, C. F. 2017. Spatiotemporal evolution of land subsidence around a subway using InSAR time-serious and the entroy method. GISci. Remote sensing. 54(1), pp. 78-94.

De Zan, F., Prats-Iraola, P., Scheiber, R. and Rucci, A., 2014. Interferometry with TOPS: Coregistration and Azimuth Shifts. EUSAR 2014; 10th European Conference on Synthetic Aperture Radar; Proceedings of. pp. 1-4.

Ferretti, A., Prati, C., \& Rocca, F. 2001. Permanent scatterers in SAR interferometry. IEEE Transactions on Geoscience and Remote Sensing, 39(1), pp. 8-20.
Ge, D.Q., Zhang, L., Li, M., Liu, B., Wang, Y. 2016. Beijing subway tunnelings and high-speed railway subsidence monitoring with PSInSAR and TerraSAR-X data. In Proceedings of the 2016 IEEE International Geoscience and Remote Sensing Symposium, Beijing, China, pp. 10-15.

Holzner, J., Bamler, R. 2002. Burst-Mode and ScanSAR Interferometry. IEEE Transactions on Geoscience and Remote Sensing, 40(9), pp. 1917-1934.

Hooper, A. 2008. A multi-temporal InSAR method incorporating both persistent scatterer and small baseline approaches. Geophysical Research Letters, 35(16), pp. 96-106.

Kang, Y., Zhao, C.Y., Zhang, Q., Lu, Z., Li, B. 2017. Application of InSAR techniques to an analysis of the Guanling landslide. Remote Sensing, 9(10),1046.

Lanari, R., Mora, O., Manunta, M., Mallorqui, J. J., Berardino, P., Sansosti, E. 2004. A small-baseline approach for investigating deformations on full-resolution differential SAR interferograms. IEEE Transactions on Geoscience and Remote Sensing, 42(7), pp. 1377-1386.

Liu, Y.Y., Zhao, C.Y., Zhang, Q., Yang, C.S. 2018. Complex surface deformation monitoring and mechanism inversion over Qingxu-Jiaocheng, China with multi-sensor SAR images. Journal of Geodynamics, 114, pp. 41-52.

Lu Z., Wicks Jr C. 2010. Characterizing 6 august 2007 crandall canyon mine collapse from ALOS PALSAR InSAR. Geomatics Natural Hazards \& Risk, 1(1), pp. 85-93.

Lu, Z., Dzurisin, D. 2014. InSAR imaging of Aleutian volcanoes: Monitoring a volcanic arc from space. Springer Praxis Books, Geophysical Sciences. 390 (ISBN 978-3-64200347-9, Springer, 2014).

Massonnet, D., Rossi, M., Carmona, C., Adragna, F., Peltzer, G., Feigl, K., et al. 1993. The displacement field of the Landers earthquake mapped by radar interferometry. Nature, 364(6433), pp. 138-142. 
Okada, Y. 1985. Surface deformation due to shear and tensile faults in a half-space. Bulletin of the Seismological Society of America, 75(2), pp. 1018-1040.

Peng J.B., 2012. Geohazards of Xi'an ground fissures. Science Press, Beijing (in Chinese). pp. 267-316.

Peng, J.B., Sun, X.H., Wang, W., Sun, G.C. 2016. Characteristics of land subsidence, earth fissures and related disaster chain effects with respect to urban hazards in xi'an, china. Environmental Earth Sciences, 75(16), pp. 1190.

Perissin, D.; Wang, Z.; Lin, H. 2012. Shanghai subway tunnels and highways monitoring through Cosmo-Skymed Persistent Scatterers. ISPRS-J. Photogramm. Remote Sensing. 73(3), pp. 58-67.

Qu F.F., Zhang Q, Lu Z, et al. 2014. Land subsidence and ground fissures in Xi'an, China 2005-2012 revealed by multiband InSAR time-series analysis. Remote Sensing of Environment, 155, pp. 366-376.

Sowter, A., Amat, M. B. C., Cigna, F., Marsh, S., Athab, A., \& Alshammari, L. 2016. Mexico City land subsidence in 2014-2015 with Sentinel-1 IW TOPS: Results using the Intermittent SBAS (ISBAS) technique. International Journal of Applied Earth Observation \& Geoinformation, 52, pp. 230242.

Xu, B., Feng, G.C., Li, Z.W., Wang, Q.J., Wang, C.C., Xie, R.A. 2016. Coastal subsidence monitoring associated with land reclamation using the Point Target Based SBAS-InSAR method: A case study of Shenzhen, China. Remote Sensing. $8(8), 652$.

Zhang Q, Zhao C.Y., Ding X.L., 2009., et al. Research on recent characteristics of spatial-temporal evolution and mechanism of Xi'an land subsidence and ground fissure by using GPS and InSAR techniques. Chinese Journal of Geophysics, 52(5), pp. 1214-1222.

Zhao C.Y., Zhang Q, Ding X.L., et al. 2008. InSAR based evaluation of land subsidence and ground fissure evolution at Xi'an. Journal of Engineering Geology, 17(3), pp. 389-393.

Zhao C Y, Zhang Q, Ding X L, et al, 2009. Monitoring of land subsidence and ground fissures in Xi'an, China 20052006: mapped by SAR interferometry. Environmental Geology, 58(7), pp. 1533-1540.

Zhu, Y. Q., Cheng, H. B., \& Jiang, Z. S. 2005. The tectonic deformation and segmented features of Lintong-Changan fracture zone. Earthquake Research in Plateau (in Chinese), 17(3), pp. 18-26. 